\title{
YKL-40 in asthmatic patients, and its correlations with exacerbation, eosinophils and immunoglobulin $\mathrm{E}$
}

\author{
H. Tang*, , Z. Fang*, , Y. Sun*, B. Lï*, Z. Shi*, J. Chen*, T. Zhang* and Q. Xiu*
}

ABSTRACT: The chitinase-like protein YKL-40, which binds chitin but lacks chitinase activity, has been found to be either the cause or a biomarker for asthma. The aim of our study was to investigate whether serum YKL-40 levels are increased in Chinese patients with asthma and identify its correlation to acute exacerbation, total serum immunoglobulin $(\mathrm{Ig}) \mathrm{E}$, the percentage of peripheral blood eosinophils and lung function. We quantified serum YKL-40 levels, total IgE levels and peripheral blood eosinophil percentages in patients with asthma, as well as in controls from the communities surrounding our hospital. The lung function of asthma subjects was also measured. Our data showed that the serum YKL-40 levels were significantly elevated in patients with asthma compared with controls and, when the asthma subjects were stratified, serum YKL-40 levels in the exacerbation group were higher than those in the stable and control groups. In addition, serum YKL-40 levels correlated positively with total serum IgE levels and the percentage of peripheral blood eosinophils, but correlated inversely with lung functions. Thus, we conclude that YKL-40 is found in increased quantities in the serum of Chinese patients with asthma, and its level correlates with exacerbation attacks, indicating that high levels of serum YKL-40 may be a biological characteristic of the exacerbation of asthma.

KEYWORDS: Asthma, CHI3L1, exacerbation, immunoglobulin E, YKL-40

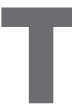

he chitinase-like protein YKL-40, also called human cartilage glycoprotein 39 (HCgp-39) and chitinase 3 -like 1 (CHI3L1), binds chitin but is deficient in chitinase activity. It is produced at sites of inflammation in many cells and is secreted from vascular smooth muscle cells and macrophages [1]. Previous studies have demonstrated that the expression level of YKL-40 was increased during T-helper cell (Th) type 2 inflammation [2]. Furthermore, it is suggested that YKL-40 has a role in inflammation and tissue remodelling in human diseases, such as joint injury, liver fibrosis, type 2 diabetes etc. [1, 3, 4]. As current concepts of pathogenesis centre on the notion that asthma is the result of exaggerated Th2 airway inflammation, and airway remodelling is an important pathological feature of asthma, YKL40 is believed to have a role in the pathogenesis of asthma, and attracts the attention of many collaborative groups. A recent study by CHUPP et al. [5] established that YKL-40 levels were increased in the lung and circulation of patients with severe asthma. Thereby, they reasoned that YKL-40 could either be a cause or marker for asthma. KUEPPER et al. [6] also showed that YKL-40 concentrations predominantly increased at the site of allergen deposition in response to allergen challenge. However, whether serum YKL-40 levels are stable or increased during exacerbations of asthma still needs to be investigated. Additionally, all the data compiled for YKL-40 and asthma come from white, black and Latino ethnic groups; there are no data for the Asian ethnic group. In our study, we measured the levels of serum YKL-40 in 62 patients with asthma and 64 controls in the Chinese population and compared the findings of the exacerbation group with those from the stable group and controls. Furthermore, the relationships between the serum YKL-40 levels, total serum immunoglobulin (Ig)E, percentage of peripheral blood eosinophils and lung function were also investigated.

\section{METHODS}

\section{Study design and subjects}

This case-control study was conducted on 62 asthmatic patients recruited from Changzheng Hospital, Second Military Medical University (Shanghai, China) over a period of 24 months, starting in March 2006 and ending in February 2008. The diagnosis of asthma was based on established guidelines [7]. 64 healthy people

\section{AFFILIATIONS}

*Dept of Respiratory Disease, Changzheng Hospital,

\#Dept of Burn Surgery, Changhai Hospital, Second Military Medical University, Shanghai, China. "Both authors contributed equally

CORRESPONDENCE

Q. Xiu

Dept of Respiratory Disease, Changzheng Hospital Second Military Medical University 415 Fengyang Road Shanghai 200003 China E-mail: xiuqing_yu@126.com

Received:

Feb 272009

Accepted after revision: Oct 202009 
TABLE 1 Patient characteristics

\begin{tabular}{|c|c|c|c|c|c|c|}
\hline \multirow[t]{2}{*}{ Characteristics } & \multirow[t]{2}{*}{ Controls } & \multicolumn{3}{|c|}{ Patients with asthma } & \multicolumn{2}{|c|}{ p-values } \\
\hline & & All & Stable & Exacerbation & $\begin{array}{c}\text { For controls versus } \\
\text { all patients }\end{array}$ & $\begin{array}{c}\text { For stable versus } \\
\text { exacerbation }\end{array}$ \\
\hline Patients n & 64 & 62 & 16 & 46 & & \\
\hline Age yrs & $42.2 \pm 11.9$ & $40.1 \pm 18.6$ & $30.9 \pm 21.8$ & $43.3 \pm 16.6$ & 0.41 & 0.06 \\
\hline Eosinophils in WBC \% & $2.92 \pm 1.88$ & $5.29 \pm 4.33$ & $5.26 \pm 1.90$ & $5.30 \pm 4.92$ & 0.001 & 0.26 \\
\hline FEV $1 /$ FEV 1 predicted & & & $0.96 \pm 0.05^{\#}$ & $0.68 \pm 0.14^{\circ}$ & & $<0.001$ \\
\hline
\end{tabular}

Data are presented as mean \pm SD or $n(\%)$, unless otherwise stated. IgE: immunoglobulin; WBC: white blood cells; FEV1: forced expiratory volume in $1 \mathrm{~s}$. Continuous data were compared using the Kruskal-Wallis test and categorical data were compared using Pearson's chi-squared test. \#: Data are missing for three subjects; ": data are missing for one subject.

without allergic manifestations were studied as controls. The characteristics of the patients and controls are shown in table 1. Asthmatic subjects were divided into two subgroups.

\section{Exacerbation group}

Asthmatic patients who requested urgent medical care for an acute exacerbation of asthma were recruited for the exacerbation group after presenting to a clinic or emergency room. Acute exacerbation of asthma was defined as the following: episodes of a rapidly progressive increase in shortness of breath, cough, wheezing or chest tightness, or a combination of these symptoms necessitating a non-scheduled visit, associated with a decrease in respiratory airflow quantified by measurements of forced expiratory volume in $1 \mathrm{~s}$ (FEV1) [7]. In our study, asthmatic patients with exacerbation were enrolled only when FEV1 was $<90 \%$ of the predicted value. Those patients who had the concomitant diseases of cancer, arthritis, hepatic fibrosis and type 2 diabetes, and those who received oral corticosteroids or had had pneumonia within the preceding 4 weeks were excluded from the study. Blood samples from the exacerbation group were collected within $6 \mathrm{~h}$ after the medical visit.

\section{Stable group}

The age-matched patients with stable asthma were recruited during their scheduled clinic visit. Their symptoms and FEV1 were stable. The enrolled patients experienced no change in their treatment course for at least 4 weeks and also had no evident asthma exacerbations during that same time period. Blood samples were collected during the scheduled clinic visit.

Our studies were approved by the human investigation committee at our institution (Changhai Hospital, Second Military Medical University, Shanghai, China). All subjects gave written informed consent.

\section{Measurement of serum YKL-40 and total IgE levels}

Measurement of serum YKL-40 levels was performed in duplicate using commercially available ELISA kits for YKL-40 (Quidel, San Diego, CA, USA). Median values are presented. The minimum detection limit of the YKL-40 assay is
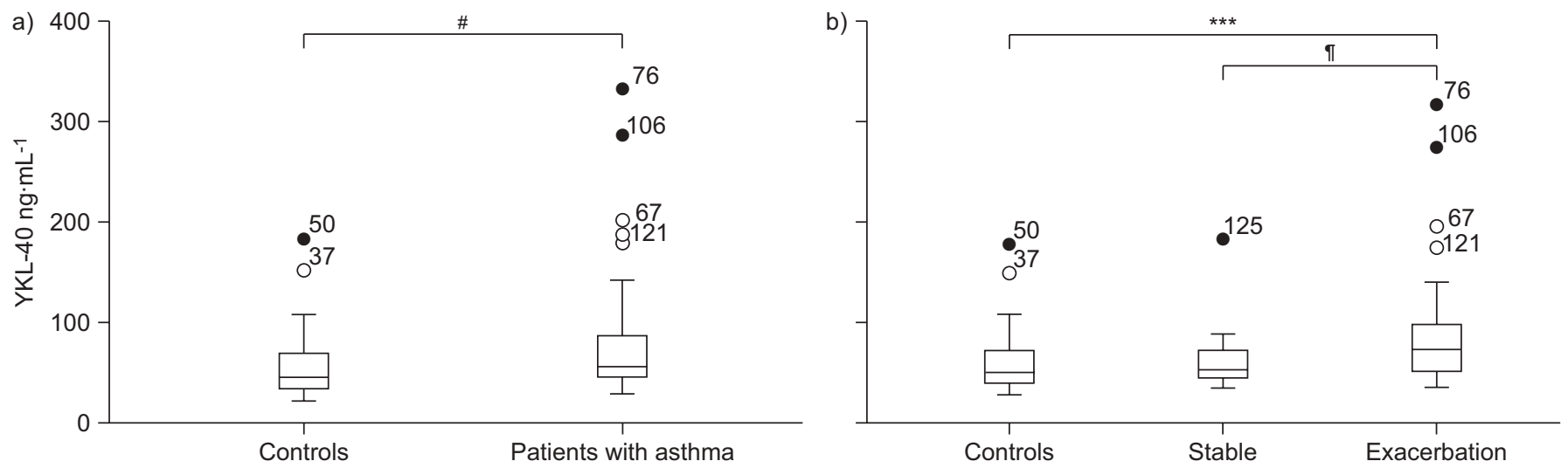

FIGURE 1. Serum YKL-40 levels in asthmatic patients and controls. The levels of circulating YKL-40 were assessed in patients with asthma and controls. a) The serum YKL-40 levels in patients with asthma were higher than those in controls. b) When patients were stratified according to exacerbation attacks, the serum YKL-40 levels in patients in the exacerbation group were higher than those in the control group and those in the stable group. Data are presented as median (horizontal line in each box), with 25th and 75th percentiles (top and bottom of each box) and 10th and 90th percentiles (top and bottom of each bar) and outliers ( $0:>3$ quartile deviations; $\bullet:>6$ quartile deviations). ${ }^{*}: p=0.003 ;{ }^{* \star *}: p=0.001 ; ": p=0.043$. 
$20 \mathrm{ng} \cdot \mathrm{mL}^{-1}$. Total serum $\mathrm{IgE}$ levels were detected once by a fluoroenzyme immunoassay (ImmunoCAP ${ }^{\mathrm{TM}}$; Phadia AB, Uppsala, Sweden) from patients with asthma and controls. The percentage of peripheral blood eosinophils was also determined using a routine blood test in each patient and control.

\section{Statistical analysis}

Analyses were performed using SPSS software, version 13.0 (SPSS, Chicago IL, USA). YKL-40 levels were not normally distributed and the values were compared among the study groups with the use of the nonparametric tests, including the Mann-Whitney U-test and the Kruskal-Wallis H-test. YKL-40 levels were expressed as median and interquartile range. Simple associations between serum YKL-40 levels, total serum IgE, the percentage of peripheral blood eosinophils and lung function were assessed using Spearman's rank correlation analysis.

\section{RESULTS}

There were significant differences between the controls and patients with asthma for total serum IgE levels and the percentage of peripheral blood eosinophils, which are two characteristics closely associated with asthma [8,9]. Compared with patients in the stable group, those in the exacerbation group had more severely compromised lung function (table 1). The serum YKL-40 levels in patients with asthma were higher than those in the controls (median (interquartile range) 77.66 $(45.75-87.00) \mathrm{ng} \cdot \mathrm{mL}^{-1} \quad$ versus $55.16 \quad(34.25-70.75) \mathrm{ng} \cdot \mathrm{mL}^{-1}$; $\mathrm{p}=0.003$; fig. 1a). When the relationship between serum YKL40 levels of the stratified groups and those of the control group were evaluated, we found that the serum YKL-40 levels for patients in the exacerbation group were higher than those in control group (83.72 (47.00-97.25) $\mathrm{ng} \cdot \mathrm{mL}^{-1}$ versus $55.16(34.25-$ $\left.70.75) \mathrm{ng} \cdot \mathrm{mL}^{-1} ; \mathrm{p}=0.001\right)$ and those in the stable group $(83.72$ $(47.00-97.25) \mathrm{ng} \cdot \mathrm{mL}^{-1}$ versus $60.25 \quad(39.00-72.75) \mathrm{ng} \cdot \mathrm{mL}^{-1}$; $\mathrm{p}=0.043)$. The serum YKL-40 levels of patients in the stable group were not higher than those in control group (median $60.25(39.00-72.75) \mathrm{ng} \cdot \mathrm{mL}^{-1}$ versus $55.16(34.25-70.75) \mathrm{ng} \cdot \mathrm{mL}^{-1}$; $\mathrm{p}=0.58)$ (fig. 1b).

In patients with asthma, the correlation between serum YKL-40 levels, total serum IgE levels, the percentage of peripheral blood eosinophils and the ratio of prebronchodilator FEV1 to the predicted value were investigated. The findings revealed that serum YKL-40 levels correlated with serum IgE levels $(\mathrm{r}=0.298, \mathrm{p}=0.018)$ (fig. 2a), the percentage of peripheral blood eosinophils ( $r=0.272, p=0.032)$ (fig. $2 b$ ) and the ratio of $F E V 1$ to the predicted value $(\mathrm{r}=-0.44, \mathrm{p}=0.001)$ (fig. $2 \mathrm{c}$ ).

\section{DISCUSSION}

Chitin, a polymer of $\mathrm{N}$-acetylglucosamine, is the second most abundant polysaccharide in nature. It is found in the walls of fungi; the exoskeleton of crabs, shrimp and insects; the microfilarial sheath of parasitic nematodes; and the lining of the digestive tracts of many insects [10,11]. Chitin accumulation is regulated by the balance of chitin synthase-mediated biosynthesis and degradation by chitinases [12]. Although humans do not have chitin and chitin synthase, studies have shown that they do express true chitinases, including acidic mammalian chitinase and chitotriosidase [11, 13]. YKL-40 is a chitinase-like protein that is also expressed in humans. It binds chitin but has no chitinase activity. The protein was named
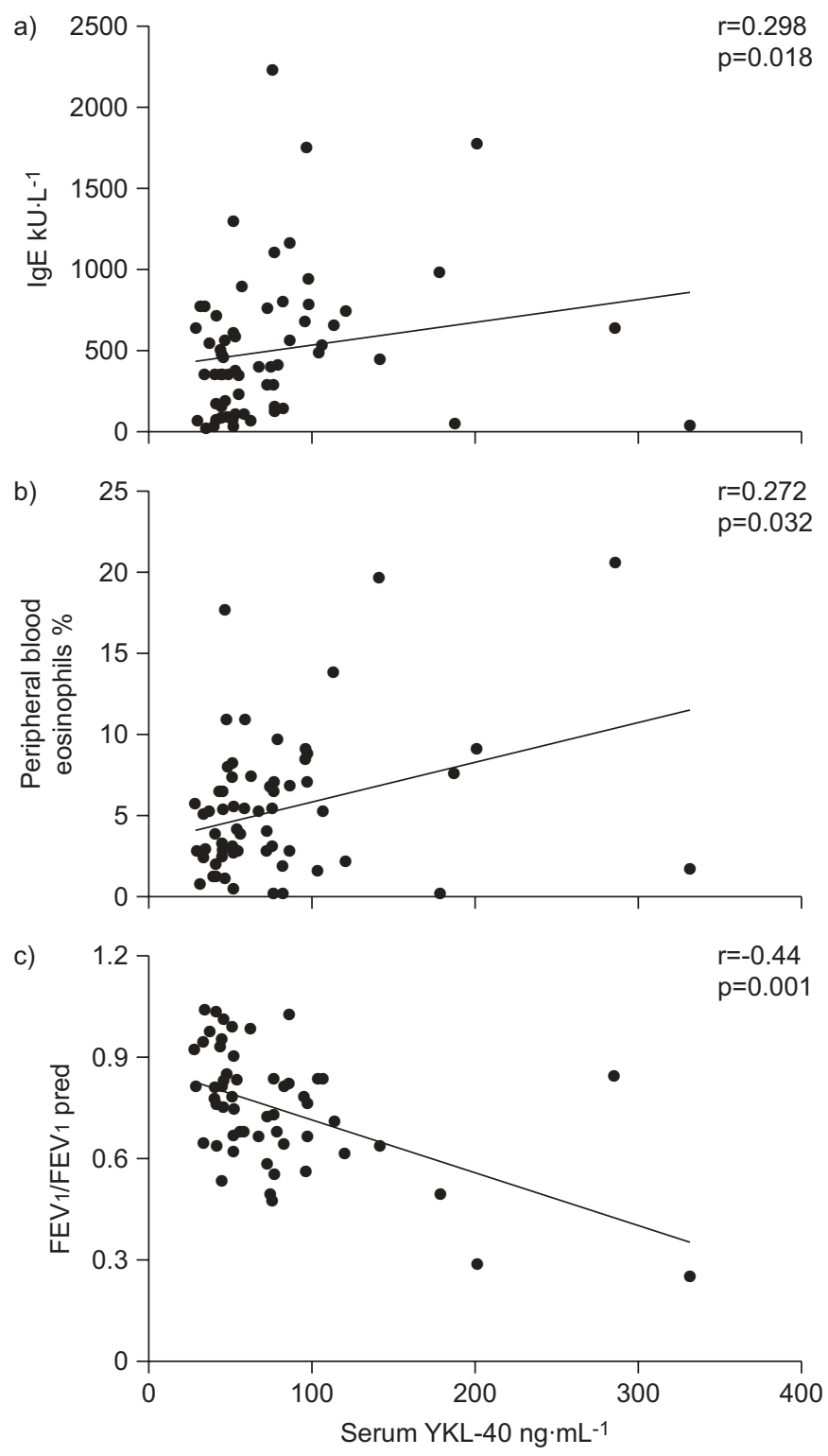

FIGURE 2. Correlation of serum YKL-40 levels with several associated items. Spearman's rank correlation analysis showed a significant correlation between the serum YKL-40 levels. a) The total serum immunoglobulin (lg)E levels ( $r=0.298$, $p=0.018)$; $b)$ the percentage of peripheral blood eosinophils $(r=0.272, p=0.032)$; c) forced expiratory volume in $1 \mathrm{~s}(\mathrm{FEV} 1) /$ predicted value $(r=-0.44, p=0.001)$.

YKL-40 based on its three N-terminal amino acids tyrosine $(\mathrm{Y})$, lysine $(\mathrm{K})$ and leucine $(\mathrm{L})$, and its molecular mass of $40 \mathrm{kDa}$ [14]. A role for YKL-40 in inflammation and tissue remodelling has been suggested previously [2]. Elevated circulating YKL-40 levels were proved to be present in patients with meningitis, pneumonia, rheumatoid arthritis, osteoarthritis, breast or lung cancer, and hepatic fibrosis $[4,15,16]$. Furthermore, CHupp et al. [5] have recently demonstrated that YKL-40 is strongly upregulated in the airway epithelium and alveolar macrophages of patients with asthma, and that serum YKL-40 levels are elevated in patients with asthma. Circulating YKL-40 levels are correlated with asthma severity, the thickness of the subepithelial basement membrane and pulmonary function, 
suggesting that circulating YKL-40 levels are a biomarker for asthma [5]. Additionally, KUEPPER et al. [6] showed that YKL-40 concentrations increased in response to allergen challenge predominantly at the site of allergen deposition.

Our study manifests that in the Chinese population, circulating levels of YKL-40 are increased in patients with asthma compared with healthy people. When the asthma subjects are stratified, circulating levels of YKL-40 in the exacerbation group are higher than those in the stable and healthy groups, which suggests that serum levels of YKL-40 correlate with asthma exacerbation attacks. In addition, the serum YKL-40 levels correlate positively with total serum IgE levels and the percentage of peripheral blood eosinophils, and correlate inversely with lung functions. Our data showing the comparison of serum YKL-40 levels between asthma and healthy subjects, and the correlation between the protein levels and lung functions coincide with those from the study of CHUPP et al. [5]. A recent study by SoHN et al. [17] suggested that in an East Asian population (Korean children), no significant associations between CHI3L1 single nucleotide polymorphisms (SNPs) and asthma were observed, while a SNP (g.-247C/T) was found to be associated with atopy and serum YKL-40 levels. Although this study did not compare the serum YKL-40 levels of asthmatic subjects with those of healthy controls directly, it seemed that there were no associations between serum YKL-40 levels and asthma. The basis for this potential discrepancy may be due to the differences in the mean ages of the subjects, since some children with atopy may develop asthma with increasing age.

In our study, we showed that when exacerbation attacks, serum YKL-40 levels of patients with asthma are higher than those of the stable period and healthy persons, and illustrated the protein's correlations with total serum $\operatorname{IgE}$ and the percentage of peripheral blood eosinophils among Chinese asthmatic patients. However, perspective studies will be required in order to determine whether the serum levels of YKL-40 would decline when those exacerbation subjects are completely controlled after treatments; this is the aim of our further efforts. Although the pathogenetic role of YKL-40 in asthma remains unclear, our study indicates that high levels of serum YKL-40 may be a biological characteristic of asthma exacerbation.

\section{STATEMENT OF INTEREST}

None declared.

\section{ACKNOWLEDGEMENTS}

The authors would like to thank L. Zhang (Department of Clinical Laboratory, Changzheng Hospital, Shanghai, China) for technical assistance.

\section{REFERENCES}

1 Rathcke CN, Johansen JS, Vestergaard H. YKL-40, a biomarker of inflammation, is elevated in patients with type 2 diabetes and is related to insulin resistance. Inflamm Res 2006; 55: 53-59.

2 Lee CG HR, Lee GR, Flavell RA, et al. Generation and use of breast regression protein (BRP)-39 null mice to define the role(s) of BRP39 in Th2 inflammation and IL-13-induced inflammation and remodeling. Am J Respir Crit Care Med 2007; 175: A253.

3 Johansen JS, Jensen HS, Price PA. A new biochemical marker for joint injury. Analysis of YKL-40 in serum and synovial fluid. $\mathrm{Br} J$ Rheumatol 1993; 32: 949-955.

4 Kelleher TB, Mehta SH, Bhaskar R, et al. Prediction of hepatic fibrosis in $\mathrm{HIV} / \mathrm{HCV}$ co-infected patients using serum fibrosis markers: the SHASTA index. J Hepatol 2005; 43: 78-84.

5 Chupp GL, Lee CG, Jarjour N, et al. A chitinase-like protein in the lung and circulation of patients with severe asthma. $N$ Engl J Med 2007; 357: 2016-2027.

6 Kuepper M, Bratke K, Virchow JC. Chitinase-like protein and asthma. N Engl J Med 2008; 358: 1073-1075.

7 Global Initiative for Asthma (GINA). Global Strategy For Asthma Management and Prevention. http://ginasthma.org/ Date last accessed: October 23, 2006. Date last updated: October 23, 2006.

8 de Marco R, Marcon A, Jarvis D, et al. Prognostic factors of asthma severity: a 9-year international prospective cohort study. J Allergy Clin Immunol 2006; 117: 1249-1256.

9 Leung TF, Wong GW, Ko FW, et al. Clinical and atopic parameters and airway inflammatory markers in childhood asthma: a factor analysis. Thorax 2005; 60: 822-826.

10 Shibata Y, Foster LA, Bradfield JF, et al. Oral administration of chitin down-regulates serum IgE levels and lung eosinophilia in the allergic mouse. J Immunol 2000; 164: 1314-1321.

11 Boot RG, Blommaart EF, Swart E, et al. Identification of a novel acidic mammalian chitinase distinct from chitotriosidase. J Biol Chem 2001; 276: 6770-6778.

12 Zhu Z, Zheng T, Homer RJ, et al. Acidic mammalian chitinase in asthmatic Th2 inflammation and IL-13 pathway activation. Science 2004; 304: 1678-1682.

13 Elias JA, Homer RJ, Hamid Q, et al. Chitinases and chitinase-like proteins in $\mathrm{T}(\mathrm{h}) 2$ inflammation and asthma. J Allergy Clin Immunol 2005; 116: 497-500.

14 Johansen JS, Williamson MK, Rice JS, et al. Identification of proteins secreted by human osteoblastic cells in culture. J Bone Miner Res 1992; 7: 501-512.

15 Ostergaard C, Johansen JS, Benfield T, et al. YKL-40 is elevated in cerebrospinal fluid from patients with purulent meningitis. Clin Diagn Lab Immunol 2002; 9: 598-604.

16 Nordenbaek C, Johansen JS, Junker P, et al. YKL-40, a matrix protein of specific granules in neutrophils, is elevated in serum of patients with community-acquired pneumonia requiring hospitalization. J Infect Dis 1999; 180: 1722-1726.

17 Sohn MH, Lee JH, Kim KW, et al. Genetic variation in the promoter region of chitinase 3-like 1 is associated with atopy. Am J Respir Crit Care Med 2009; 179: 449-456. 